\title{
Repensando Papéis em Equipes Ágeis: Um Estudo de Caso no Uso de uma Abordagem Combinada de Desenvolvimento Ágil, User-Centered Design e Lean Startup
}

\author{
Larissa Salerno, Ingrid Signoretti, Sabrina Marczak, Ricardo Bastos \\ ${ }^{1}$ Escola Politécnica - Pontifícia Universidade Católica do Rio Grande do Sul (PUCRS) \\ Caixa Postal 1429 - 90.619-900 - Porto Alegre - RS - Brazil \\ \{larissa.salerno, ingrid.manfrim\}@acad.pucrs.br \\ \{sabrina.marczak, bastos\}epucrs.br
}

\begin{abstract}
The combined use of User-Centered Design, Lean Startup and Agile is a promising strategy to aim for better attending user needs when developing software products. This paper reports on a case study of two software teams of a large-multinational company that, by introducing such new approach, were faced with the need of reconsidering the teams' roles and responsibilities, including defining the new role of Product Designer. The learning experience of these teams are discussed sheding some light to other practitioners on the matter.
\end{abstract}

\begin{abstract}
Resumo. Uma abordagem combinada de User-Centered Design, Lean Startup e Ágil promete garantir que o desenvolvimento do produto seja focado nas necessidades do usuário. A partir de um estudo de caso na indústria, este artigo apresenta como a introdução dessa abordagem implicou na discussão dos papéis que devem compor a equipe de desenvolvimento de software que passa a usar a referida abordagem. Compara-se estes papéis com àqueles das metologias ágeis tradicionais e discute-se o impacto da inserção do papel de Product Designer, contribuindo para o entendimento do assunto na prática.
\end{abstract}

\section{Introdução}

Gregory et al. [Gregory et al. 2016] argumenta que equipes de desenvolvimento têm encontrado dificuldades no relacionamento com a área de negócio, por precisarem mostrar, constantemente, o valor agregado que o TI traz; isto se dá, entre outras razões, pela dificuldade do cliente expressar o problema a ser resolvido e a equipe entregar uma solução que de fato resolva esse problema. Como uma forma de promover melhorias nessa relação, estudos (e.g., [Dobrigkeit and de Paula 2017] ) têm relatado a necessidade de equipes adotarem uma abordagem combinada que utiliza User-Centered Design, Lean Startup e Ágil [Dobrigkeit and de Paula 2017]. A integração dessas três abordagens tem sido apontada como promissora uma vez que o User-Centered Design [Garcia et al. 2019] fornece ao desenvolvimento ágil um roteiro para soluções criativas e centradas no usuário, enquanto o Lean Startup [Ries 2011] mantém os stakeholders envolvidos desde a concepção do produto, buscando rapidamente identificar as necessidades reais do usuário final e pivotando propostas de solução antes mesmo de iniciar o desenvolvimento de uma solução que possa vir a não ser a ideal ou necessária, focando no valor agregado ao negócio, fornece uma estrutura para validar e medir o ciclo de vida do produto. 
Com a inclusão da nova abordagem, é natural que os papéis que compõem equipes de desenvolvimento de software sejam readequados para que práticas e atividades de User-Centered Design e Lean Startup sejam inseridas. Considerando este cenário, este artigo tem como objetivo relatar um estudo de caso múltiplo no qual equipes de software em processo de transformação para a abordagem combinada estão vivenciando também a redefinição dos papéis envolvidos, incluindo a criação do novo papel de Product Designer, que visa auxiliar no melhor entendimento das necessidades e engajamento do usuário. As demais seções deste artigo discorrem sobre o estudo de caso e seus resultados, destacando as contribuições para a indústria de software.

\section{Método de Pesquisa}

Foi realizado um estudo de caso múltiplo [Yin 2017] na empresa de TI multinacional $\mathrm{ORG}^{1}$, guiado pela seguinte questão de pesquisa: Quais as mudanças nos papéis e responsabilidades na transformação de uma equipe ágil tradicional, para uma abordagem combinada de User-Centered Design, Lean Startup e Desenvolvimento Ágil?

\subsection{O Caso Estudado}

A ORG possui centros de desenvolvimento nos Estados Unidos (sede), Índia e Brasil. O departamento de TI conta com aproximadamente 7.000 funcionários responsáveis por mais de 1.200 produtos de software e por sua integração com produtos legados e de terceiros. Esse departamento iniciou sua transformação ágil no início de 2015 e passou para a integração de princípios de User-Centered Design, Lean Startup e Desenvolvimento Ágil a partir da metade de 2017. A empresa está realizando essa transformação com o intuito de garantir maior qualidade e satisfação dos usuários com os produtos desenvolvidos.

A nova abordagem adotada foi inspirada na metodologia Pivotal $\mathrm{Labs}^{2}$, da empresa Pivotal ${ }^{3}$. Inspirada nos pilares das três abordagens, a Pivotal Labs utiliza o conceito de equipes multifuncionais (ou multidisciplinares), trazendo a proposta de adoção dos papéis de Product Designer, Product Manager e Software Engineer para compor uma equipe de produto de software. O livro guia da Pivotal Labs ${ }^{4}$ introduz os papéis, ferramentas e métodos articulados pela Pivotal baseado nos princípios das três abordagens e na experiência de quase 10 anos de prestação de consultoria no mercado de desenvolvimento de software mundial, com foco em organizações de grande porte. O guia tem o intuito de ajudar equipes a criar produtos que entreguem valor para os usuários e clientes. Assim, o guia oferece um ponto de partida inicial para qualquer equipe discutir suas necessidades específicas e definir seu próprio caminho para o desenvolvimento do produto.

Diante deste processo de adoção, a ORG criou uma equipe global para liderar a transformação, responsável por definir estratégias para disseminar a nova abordagem para o restante da empresa e garantir que as metas organizacionais estão sendo atendidas. Essa equipe definiu um conjunto de workshops para explicar aos colaboradores os princípios das três abordagens e como a transformação passa a fazer parte do dia-a-dia das equipes de produto de software. Também foram elaborados materiais com uma introdução às novas

\footnotetext{
${ }^{1}$ Pseudônimo por razões de confidencialidade.

${ }^{2}$ https://pivotal.io/labs

${ }^{3}$ https://pivotal.io

${ }^{4} \mathrm{~A}$ versão completa do guia é de acesso restrito, mas apresentado em sua essência no site da abordagem.
} 
práticas, técnicas e atividades sendo adotadas ou recomendadas, denominados cookbooks. Em paralelo, as equipes participam de um programa de imersão para o aprendizado da nova abordagem sob a tutoria direta de colaboradores da Pivotal especializados no Pivotal Labs. Esses "tutores" atuam por um período de 12 semanas in-loco como parte da equipe de desenvolvimento no intuito de ajudar os integrantes da equipe a aprenderem na prática (da expressão do inglês, learn on the job). A imersão ocorre na sede da empresa nos Estados Unidos com as equipes trabalhando em projetos de seu próprio backlog.

Esses novos facilitadores estão aplicando o programa de imersão para as novas equipes no Brasil em um laboratório construído em parceria entre ORG e PUCRS. Localizado no campus da Universidade, o ambiente foi criado especialmente para os programas de imersão, onde as equipes possam ficar livres e isoladas para experimentar e aprender sem interferências de outros colegas que ainda não estejam participando da transformação. O laboratório possui uma infraestrutura similar a sugerida pela Pivotal Labs para trabalho colaborativo, (e.g., mesas dispostas para trabalhos em pares, telas grandes de TV móvel, quadros brancos e móveis, e uma mesa de reuniões convertida em mesa de ping-pong para momentos de lazer e descontração.

\subsection{Coleta de Dados e Procedimentos de Análise}

Utilizou-se as seguintes técnicas de coleta de dados: questionário para coletar as informações referentes ao perfil dos participantes (nome, papel, responsabilidades, tempo de trabalho em anos com TI e na empresa, se a pessoa participou da imersão nos EUAidentificado como Facilitador ou está sendo capacitado no Brasil-“Em capacitação"); entrevistas semi-estruturadas; e observações diárias visando observar as cerimônias realizadas pelas equipes. Foram realizadas observações também no formato de shadowing [Singer et al. 2008], onde um pesquisador passou entre 1 e 2 horas participando das atividades desempenhadas por um determinado participante para melhor entender a sua rotina ao desempenhar certo papel na equipe. Por fim, foram realizadas sessões de focus group com os 8 facilitadores para promover a discussão entre eles a respeito dos tópicos que emergiram dos dados coletados anteriormente. As entrevistas e as sessões de focus group foram gravadas e transcritas para posterior análise; tendo uma duração média de $30 \mathrm{~min}$ e $1.5 \mathrm{~h}$, respectivamente. Notas foram tomadas durante as observações.

Os dados foram analisados seguindo o procedimento de análise de conteúdo textual de Krippendorff [Krippendorff 2018]. O processo foi organizado nas seguintes etapas: organização e pré-análise, leitura e categorização, e registro dos resultados. Primeiro foi lido o conjunto de dados, depois foram extraídos trechos de texto os quais foram identificados como códigos. Esses códigos foram revisados e agrupados em códigos maiores, formando categorias. Os dados foram analisados utilizando a ferramenta Atlas.ti ${ }^{5}$.

\section{Resultados}

Estudou-se por 12 semanas duas equipes localizadas no laboratório experimental na PUCRS. Dos 14 participantes, que possuíam em média 14.5 anos de experiência na indústria (mínimo de 5 e máximo de 27 anos) e 6.5 anos de empresa (mínimo de 1 e máximo de 11 anos), teve-se 8 facilitadores e 6 membros em capacitação. Esses membros seguiram a sugestão da Pivotal Labs e organizaram suas equipes conforme os papéis sugeridos pela

\footnotetext{
${ }^{5}$ https://atlasti.com/
} 
Tabela 1. Mudanças apresentadas entre os papéis.

\begin{tabular}{|c|c|c|}
\hline Ágil Tradicional & Papel & Abordagem Combinada \\
\hline $\begin{array}{l}\text { - Foca no desenvolvimento da solução } \\
\text { - Recebe requisitos especificados } \\
\text { - Esclarece esses requisitos com o Product } \\
\text { Manager e, quando esse elege como cabível, com } \\
\text { a área de negócios }\end{array}$ & Software Engineer & $\begin{array}{l}\text { - Participa diretamente dos encontros com os } \\
\text { usuários } \\
\text { - Passa a discutir com os usuários as necessidades } \\
\text { solicitadas e as soluções propostas } \\
\text { - Segue responsável pela codificação mas não mais } \\
\text { pela definição da solução; que passa a ser } \\
\text { compartilhada por todos os papéis }\end{array}$ \\
\hline $\begin{array}{l}\text { - Realiza o trabalho do Product Owner no que } \\
\text { diz respeito ao entendimento do problema do } \\
\text { cliente e escopo do software } \\
\text { - Gerencia o Product Backlog } \\
\text { - Prioriza os requisitos baseado nas metas } \\
\text { organizacionais, comunicadas pela área de } \\
\text { negócios } \\
\text { - Media a conversa entre a área de negócios e } \\
\text { equipe de TI }\end{array}$ & Product Manager & $\begin{array}{l}\text { - Foca no entendimento das necessidades dos } \\
\text { usuários em relação ao negócio, validando } \\
\text { constantemente se as mesmas de fato ajudam a } \\
\text { agregar valor à empresa } \\
\text { - Passa a receber necessidades dos usuários ao } \\
\text { invés de requisitos pré-definidos da área de } \\
\text { negócios } \\
\text { - Atua direta e conjuntamente ao Product Designer } \\
\text { nesses entendimentos } \\
\text { - Ponto focal para discussão do product backlog e } \\
\text { priorização de requisitos mas já não é o único } \\
\text { responsável; essa visão passa a ser compartilhada } \\
\text { por todos os papéis }\end{array}$ \\
\hline - Inexistente & Product Designer & $\begin{array}{l}\text { - Foca na visão do usuário quando da definição e } \\
\text { desenvolvimento da solução } \\
\text { - Cria e valida métricas constantemente para indicar } \\
\text { o sucesso do projeto junto aos usuários }\end{array}$ \\
\hline
\end{tabular}

abordagem base da transformação-Product Manager, Product Designer e Software Engineer. Os papéis de Product Manager (2 facilitadores e 2 em capacitação) e Software Engineer ( 4 facilitadores e 4 em capacitação) nas equipes estudadas sofreram modificações quando comparados ao modelo ágil, inspirado no framework Scrum que a empresa utilizava. Como novidade, a empresa incluiu o papel de Product Designer (2 facilitadores) conforme preconizado pela Pivotal Labs e detalhado nessa seção.

A Tabela 1 mostra os papéis dessa abordagem combinada junto com as diferenças dos mesmos quando comparado aos papéis de antes, inspirados inicialmente no framework Scrum. As mudanças mais significativas estão relacionadas à estrutura da equipe que passa a ser multifuncional (ou um cross-functional team), tendo então, um papel específico para cada uma das áreas da abordagem combinada. Um dos impactos de ter uma equipe com essa estrutura é que todos os membros possuem a mesma visão do produto e do problema em questão. O envolvimento da equipe inteira abrange desde a concepção do produto até a entrega de fato do sistema em produção. Em um formato anterior, participava das reuniões apenas o Product Owner e este, era responsável por passar as informações para o restante da equipe. Já na nova visão, pelo menos um representante de cada área participa desta reunião, cada um explorando o seu aspecto na identificação e entendimento do problema.

O Product Designer atua na equipe como uma espécie de facilitador, de acordo com a percepção dos entrevistados. Como responsabilidades, o Product Designer ajuda a equipe na identificação dos problemas, identificação de métricas com o intuito de medir a assertividade do seu produto, criação de novos fluxos e validação com o usuário.

Como facilitadores, eles trabalham na descoberta do problema, utilizando diversas atividades e técnicas, como, por exemplo, entrevistas com o usuário; affinity clustering, 
que auxilia no agrupamento de trechos; ideias que podem surgir tanto das entrevistas com o usuário quanto de sessões de brainstorming; two by two, que procura compreender o impacto e a dificuldade do problema, através de uma matriz 2 por 2; user journey mapping que procura relacionar a jornada do usuário com relação ao produto; entre outras.

Com a descoberta do problema e o entendimento sobre o mesmo, o Product Designer conduz a equipe no entendimento e na descoberta da melhor solução. Ou seja, mesmo que todos os papéis estejam envolvidos nas reuniões, o Product Designer é o responsável por guiar essas discussões. No estudo, os membros das equipes destacaram uma série de observações em relação ao papel do Product Designer dentro das equipes.

Um dos aspectos citados pelos membros foi sobre como o contato maior com o usuário traz maior qualidade ao produto, e também sobre a importância do papel do Product Designer na hora de auxiliar as equipes a criarem empatia com os usuários. Para os membros, esses fatores fazem com que a equipe acabe focando diretamente nas necessidades do usuário.

Também foi ressaltada a diferença entre o papel de Product Manager e Product Designer, onde o primeiro foca no negócio e o outro no usuário, tirando o foco único no cliente, como costumava se organizar a empresa, mas sempre trabalhando conjuntamente para desenvolver ambas visões.

\section{Discussão}

O estudo de caso buscou identificar quais mudanças ocorreram entre os papéis e suas responsabilidades com a adoção da abordagem combinada pela ORG. A equipe passou a ter uma visão compartilhada do produto [Kuusinen et al. 2017], em função da mudança em sua estrutura que passa a ser multifuncional. Outra mudança significativa está relacionada a inserção do papel do Product Designer que impactou diretamente nas responsabilidade de todos os papéis, pois agora todos passam a desenvolver o produto centrado no usuário. Garcia, da Silva e Silveira [Garcia et al. 2019] falam sobre a importância em ter uma pessoa que foca no usuário durante todo o processo de desenvolvimento do produto.

A equipe enfatiza que a presença do usuário durante o desenvolvimento do produto garante, consequentemente, um produto desenvolvido com maior qualidade, aspecto observado por Abelein, Sharp e Paech [Abelein et al. 2013]. Visto isso, é notória que a inserção do papel de Product Designer foi o fator que conduziu as maiores mudanças com relação as responsabilidades de todos os papéis. A equipe passa a participar desde a a concepção do produto buscando entender o problema do usuário e, o Product Designer passa a ser um facilitador conduzindo a equipe no uso de técnicas oriundas do User-Centered Design, o que cria o senso na equipe de focar nas necessidades do usuário.

\section{Considerações Finais}

O objetivo desse artigo foi identificar as mudanças que ocorreram nos papéis de trabalho de equipes em processo de transformação que adotaram uma metologia que usa UserCentered Design, Lean Startup e Desenvolvimento Ágil. Além de reconsiderar os papéis já atuantes nas equipes ágeis (tradicionais apenas), as equipes também introduziram um novo papel, o de Product Designer, e redistribuíram responsabilidades entre os papéis existentes e o novo papel definido. Como consequência dessa reconsideração, os participantes do estudo concluíram que: 
- Toda a equipe passou a participar desde a concepção do problema até a definição e desenvolvimento da solução

- Notou-se um maior engajamento do usuário

- Facilitou o estabelecimento da empatia com o usuário

- Product Designer como crucial na identificação de melhores soluções aos problemas dos usuários

Inerente a qualquer estudo de natureza empírica, o presente estudo apresenta limitações. Quanto à generalização dos resultados, as duas equipes investigadas são de uma empresa multinacional, com a adoção recente em métodos ágeis (2015) e na abordagem combinada (meados de 2017). As equipes observadas, em específico, estão engajadas na transformação por apenas 6 meses ( 3 na imersão nos EUA e 3 no laboratório na PUCRS). Assim, o entendimento das responsabilidades estabelecidas está ainda em evolução e não pode ser considerado uma solução para qualquer cenário. Mas já é possível uma reflexão e discussão inicial a demais interessados considerando a experiência prática e o sucesso dos produtos desenvolvidos, conforme apontado pelos próprios usuários das equipes estudadas. Para aprofundar o entendimento do fenômeno e expandir para outros cenários de atuação, vai-se acompanhar outras quatro equipes no decorrer dos próximos seis meses, como parte do escopo do projeto de pesquisa, visando identificar os efeitos da transformação a longo prazo.

\section{Referências}

Abelein, U., Sharp, H., and Paech, B. (2013). Does involving users in software development really influence system success? IEEE Software, vol. 30:pp. 17-23.

Dobrigkeit, F. and de Paula, D. (2017). The best of three worlds: The creation of innodev, a software development approach that integrates design thinking, scrum and lean startup. In Proceedings of the 21st International Conference on Engineering Design, pages 319-328, Vancouver, Canada. Design Society.

Garcia, A., da Silva, T. S., and Silveira, M. S. (2019). Artifact-facilitated communication in agile user-centered design. In Agile Processes in Software Engineering and Extreme Programming, pages 102-118, Montreal, Canada. Springer.

Gregory, P., Barroca, L., Sharp, H., Deshpande, A., and Taylor, K. (2016). The challenges that challenge: Engaging with agile practitioners' concerns. Information and Software Technology, 77:92 - 104 .

Krippendorff, K. (2018). Content Analysis: An Introduction to Its Methodology. Sage, New York, NY, USA.

Kuusinen, K., Gregory, P., Sharp, H., Barroca, L., Taylor, K., and Wood, L. (2017). Knowledge sharing in a large agile organisation: A survey study. In Int'l Conf on Agile Software Development, pages 135-150, Germany.

Ries, E. (2011). The Lean Startup: How Today's Entrepreneurs Use Continuous Innovation to Create Radically Successful Businesses. Crown Business, Danvers, MA, USA.

Singer, J., Sim, S. E., and Lethbridge, T. C. (2008). Software Engineering Data Collection for Field Studies. Springer, London.

Yin, R. K. (2017). Case study Research and Applications: Design and Methods. Sage publications, Thousand Oaks, CA, USA. 